\title{
CORPORATE APPLICATION OF SOCIAL MEDIA IN THE LIFE OF SMALL AND MEDIUM-SIZED ENTERPRISES
}

\author{
Enikő KORCSMÁROS ; Bence CSINGER
}

J. Selye University, Faculty of Economics and Informatics

\begin{abstract}
:
Purpose: The field of research of corporate social media is in many respects related to the topic of zero waste management and the circular economy, as by applying it a company can make a great contribution to environmental protection. The aim of our study is to examine the importance that small and medium-sized enterprises operating in two regions of Slovakia attach to corporate social media.

Design/methodology/approach: In the course of our research, we conducted a quantitative questionnaire survey in the examined SME sector. A research question was formulated on the topic: which is as follows: What importance do the leaders of small and medium-sized enterprises attach to social media in the life of their business?

Findings: The results of our study were evaluated based on responses from 359 companies. The results suggest that although there are more small and medium-sized enterprises present on social media than not, they do not make the most of opportunities inherent in social media.

Research limitations: One of the main limitations of the study was the ongoing health crisis situation, due to which there was an inadequate willingness to complete the questionnaire sent out.

Practical implications: The results explain the question of SME sector leaders as to whether it is still worthwhile to invest time and energy nowadays in the active presence of their business in social media.

Social implications: With the help of our research, the reader can get a comprehensive picture of exactly what small and medium-sized enterprises use social media and how they are able to influence their own target audience.
\end{abstract}

Key words: corporate communication, corporate social media, marketing strategy, Slovakia, SME sector

\section{Introduction}

Social media, as a concept, includes computer-aided devices that allow for the rapid exchange of information over virtual networks. (Balan, Rege 2017, p. 43)

It is a well-known fact that the internet and social media have an extremely large impact on the operation and success of a business. The main reason for this is that online communication provides an opportunity to replace physical proximity with virtual interaction. Social media itself refers to content that is spread through social interactions. These types of media offer a means to build relationships between consumers and businesses. This is why social media needs to prove to be an important tool for any business, as it allows organizations to communicate, listen and learn with their customers in ways they have not previously had the opportunity to do. (Jones, Borgman, Ulusoy 2015, p. 611)

https://doi.org/10.11118/978-80-7509-820-7-0238 
Millions of users use social media platforms every day, which are now the primary means of communication for all age groups. (Balan, Rege 2017, p. 43)

Social media has revolutionized business by offering an optional marketing platform that has gradually grown into a growing strategy. Globalization has made it necessary for every business to reach its consumers through a network that brings people closer to organizations and makes it easier for them to shop. (Basri, Siam 2017, p. 241)

Nowadays, with the increasing use of social media, businesses have made it easier to reach potential consumers, enabling customers and stakeholders to connect virtually, engage, and feel that their opinions matter. (Webb, Roberts 2016, p. 66)

Social media has now become a topic in the lives of businesses that they cannot avoid. The primary goal of our study was to examine the role of social media in the life of small and medium-sized enterprises in the Nitra and Trnava regions. In the course of the research, three hypotheses were formulated. Our results provide a comprehensive picture of whether there is a correlation between time spent on social media and marketing costs associated with online presence, company size, and monitoring and integrating target audience feedback, and the nature of businesses 'activity and presence on social media.

\section{Literature review / Research Background}

Over the past two decades, innovation activities in the online world have played and continue to play an important role in business, as Web 2.0 applications provide an opportunity to use social media to transfer Internet capabilities to a social environment where individuals can interact online way. (Tajvidi, Karami 2021, p. 1)

The term social media includes web-based platforms that offer users the opportunity to interact, that is, unlike traditional media, they offer the opportunity for social dialogue. Social media is a tool that allows users to place and perceive different types of information and can also be used as a marketing tool that requires constant updating, i.e. a tool that is key to achieving business goals. (Grizane, Jurgelane 2017, p. 192)

Social media is present in many forms in people's lives, which includes, but is not limited to, social networks, blogs, microblogs, forums, social games, business networks, photo sharing websites, and chat applications. (Constantinescu et al., 2019, p. 2)

Social media is the most effective tool for marketing. The importance of social presence is constantly growing as it is an extremely popular and accepted online space in people's lives. Its indispensability is manifested primarily in its ability to influence billions of people around the world, which has resulted in changes in the procedures and techniques required to perform operations in the professional world. Today, being online is a must for any business, as the world has changed and communication has become one of the key keys to success. Businesses need to understand and embrace this change, because by doing and adapting to it, they are creating a number of benefits and opportunities that are a condition for future growth and development. In terms of obtaining information, people most often use social 
media. For this reason, a presence on social media is essential for business growth and development. (Li 2021, p. 961)

The corporate application of social media is changing organizational communication and public relations. The reason for this is that the online space allows for open communication, which on the one hand contributes to the understanding of consumer needs on the one hand and motivates them to respond effectively to these needs on the other hand. (Tajudeen, Jaafar, Ainin 2018, p. 308)

Social media allows marketers to influence consumers 'purchasing decisions by promoting branded content. This is significant because promoting a brand has a big impact on sales, brand awareness, brand loyalty, and social media ROI. (Swani et al. 2017, p. 77)

It is important to mention two other extremely important benefits of using social media in companies. The first is cost reduction by decreasing staff time, and the second is Increase of probability of revenue creation. The second benefit mentioned is the sharing of information and skills, the use of customer wisdom, the ability to help, and the involvement of consumers. (Sajid 2016, p. 3)

Social media offers many benefits and opportunities for businesses. The first factor worth mentioning is learning, as organizations have the opportunity to observe what their consumers are doing, what is happening in their lives, and from this they can adapt to their consumer needs and develop their marketing strategies as quickly as possible. The second factor is targeted marketing. With the help of social media, companies are able to launch targeted marketing campaigns that will result in an increase in the number of target audiences, the basic condition of which is to increase the visibility of the business, in which social media also helps. In addition, being online is much more cost effective than traditional marketing tools. However, one of the biggest benefits of online platforms is the fast, honest, and detailed feedback you receive from consumers, which allows you to respond extremely quickly to changing needs, which can give your company a competitive edge over the competition. Responding appropriately and quickly to consumer feedback can also lead to a deeper commitment and a solid consumer base is a key factor in today's unpredictable world. In terms of corporate image, social media can contribute to increasing the credibility and reputation of organizations. The next notable benefit is tracking. Online platforms allow businesses to monitor the competitive position of competing companies and access and provide vital market information and statistics. It can also be said that social media accelerates innovation as well as the development of new products, as it can facilitate knowledge transfer, which contributes to the acceleration of innovation and the development of new products, and facilitates recruitment and recruitment. It was mentioned earlier, but it is important to mention again that social media improves communication between businesses and consumers. The last notable benefit is building consumer confidence and loyalty. (Radhakrishnan, Ugalde 2019, p. 6)

Overall, information obtained through social media is a key source of both customer analysis and market research, as well as the mass acquisition of new ideas. (Li, Larimo, Leonidou 2020, p. 53) 


\section{Methodology}

Our study began in February 2021 in the form of a quantitative questionnaire survey due to the ongoing health crisis. Our study sample includes 359 companies from the Nitra and Trnava regions. Our questionnaire was prepared using Google form creation software and examined the role of social media in the SME sector with a total of 27 questions. The filling was done anonymously. In addition to demographic data, our questionnaire included questions related to presence on social media, questions about tracking and using feedback, questions about future plans, and questions about the success of traditional marketing tools.

In our research, we formulated three hypotheses, which are as follows:

1. There is a significant relationship between the time spent on social media and the marketing costs associated with social media presence.

2. The size of the company and the observation of the feedback of the target audience and their integration into the company's activities are significantly related to each other.

3. There is a significant relationship between the nature of the companies' activities and the change caused by their presence in social media.

SPSS program descriptive statistical analysis was used to examine the relationships, within which a Chi-square test was performed. A significance level of $5 \%$ was determined during the evaluation.

\section{Results}

In our research, we examined a total of 359 small and medium-sized enterprises in terms of the corporate application of social media. Based on the sample, it can be said that the companies surveyed are $66.3 \%$ micro, $26.2 \%$ small and $7.5 \%$ mediumsized and most have more than 10 years of experience in business presence. In the second part of the questionnaire, we asked companies about their presence on social media. The results showed that although $67.4 \%$ of the surveyed SME sector is present on social media, we were surprised to find that $32.6 \%$ of them are not present in the online space. Undoubtedly, businesses that are present on online platforms prefer Facebook almost $100 \%$, followed by Instagram, which is becoming increasingly popular these days. In our next question, we were wondering exactly what businesses use social media for. $75.6 \%$ of the respondents use the opportunities provided by online space in terms of providing information. They also consider it important to build brand awareness as well as expand the number of target audiences. To the question of whether the company employs a separate person (s) / outsourced company who deals with social media presence. Most (74\%) answered in the negative. We were also curious about how important it is in the lives of businesses to be present on social media. Respondents had the opportunity to answer the question on a 5-point Likert scale. Most responses chose option three, suggesting that social media presence is neutral for most businesses, however, there were far 
more responses to options 4 and 5 than to options 1 and 2. that is, although neutral for most companies, presence is more important than not being present. The results also show that it is important for organizations to be online, primarily to reach new consumers, but also to provide information and awareness. As mentioned earlier, we formulated three hypotheses on the topic during the analysis. For the first hypothesis, we hypothesized a relationship between time spent on social media and marketing costs associated with social media. In the Chi-square test, we obtained 0.012, i.e., we rejected the null hypothesis, which assumes that there is no relationship between the variables, and accepted the alternative hypothesis, i.e., our assumption was confirmed. For the second hypothesis, we wondered whether there was a relationship between the size of the firm and the observation of feedback from the target audience and integration into firm activities. In this case, we obtained 0.002 , ie our assumption was confirmed in this case as well, because the two variables are significantly related to each other. In the last hypothesis, we hypothesized that there is a significant correlation between the nature of firms 'activities and the direction of change caused by their presence on social media. The following result was obtained: $\mathrm{P}=0.615$. The result shows that in this case the null hypothesis is acceptable because the result obtained is greater than the specified 5\% significance level, i.e. there is no relationship between the two variables. In the remainder of our questionnaire, we also placed great emphasis on whether the companies surveyed monitor the presence of competitors on social media. As a result, we found that most (41.8\%) did not monitor competition at all, but firms that did, however, were surprised to find that the largest percentage (47.9\%) did not use critical remarks made against competitors. We were also curious about what percentage of their marketing activities are spent on online presence. $70 \%$ of the SME sector surveyed are willing to invest only $0-25 \%$ in this activity.

\section{Discussion}

In the theoretical part of our study, the role and most significant benefits of the use of social media in companies are presented. In their 2015 study, Jones, Borgman, Ulusoy explained that social media should prove to be an important tool for any business. In our research, we found that for the entrepreneurs surveyed, in addition to the fact that most people consider online space to be moderately important, there are far more people who consider it more important than those who do not. It has been mentioned earlier that learning can be one of the benefits of social media, but our research found that a large percentage of the SME sector surveyed do not use critical remarks about competitors as well as feedback from the target audience. Tracking can also be defined as a key benefit, but our results show that a huge number of businesses today do not place much emphasis on taking advantage of the online space, although, as mentioned in the theoretical review, businesses can access vital market information and statistics. In today's knowledge-based society, where speed of information and adaptation is the basis of competitive advantage, businesses need to take advantage of the opportunities offered by social media. In addition to the benefits mentioned earlier, it is important to mention that social media is also an 
important area of research for the environment, zero waste management and the circular economy. From a corporate point of view, great emphasis must be placed on this topic, as by applying it, companies can take advantage of the possibility of launching marketing campaigns that take place exclusively in the online space, with which they make a great contribution to environmental protection. It is also important to emphasize that this type of corporate activity reaches consumers much faster and can be modified much more easily and quickly in the event of obsolescence, without significantly polluting the environment. Overall, therefore, by having an online presence on social media, an organization can make a significant contribution to protecting the environment, as all activities take place online, so this area of research will be an important part of the future to invest.

\section{Conclusion}

In our study, we found that more than $30 \%$ of the small and medium-sized enterprises in Slovakia surveyed are not present at all on social media. In our view, the primary reason for this is that they are afraid of change, insecure about the online world, but it is important to mention that in today's world, only a business that can adapt and manage uncertainty can be successful. Social media has become an integral part of society, businesses cannot avoid it if they want to remain present in the market necessary to adapt to their target audience. Surprisingly, we found that $41.8 \%$ of the companies surveyed do not pay any attention to the presence of competitors in social media. In this regard, it is surprising that businesses need to seize every opportunity to learn, for which social media offers an extremely costeffective solution. It is important to keep in mind that you can learn a lot not only from failures, but also from successes. Furthermore, it can be said that nearly $50 \%$ of the companies surveyed do not use the feedback received from the target audience. The basis of successful operation and competitive advantage today is the appropriate background formed by the consumer base and the rapid adaptation to consumer needs. Without feedback, a business is unable to track the extremely rapid change in consumer demand. This suggests that a huge number of businesses are still unaware of the many benefits of social media that they could apply. In the case of a change since its presence on social media, it can be said that there was only a very little more response to the positive response option than no change. This is positive, as only $0.8 \%$ of businesses feel that social media has made a negative difference in their lives. Businesses that feel that there has been no change in their lives are unlikely to take advantage of all the opportunities offered by online space, which is the reason why almost $60 \%$ of the SME sector surveyed does not want to expand their presence on social media in the future.

Based on our results, it can be said that social media marketing costs are related to the extent to which the company monitors and uses the feedback from the target audience, however, the nature of the organizations' activities are not related to how the appearance on social media has brought about a change in the life of the company. In the future, our goal is to conduct an international comparative research, in which we examine small and medium-sized enterprises in Hungary and Slovakia 
on corporate integration of social media, as well as to make suggestions and provide feedback to the SME sector on the appropriate use of online platforms.

\section{References}

1. Balan S., Rege J. (2017), Mining for social media: Usage patterns of small business, „Business Systems Research", number 1., volume 8., pp. 43-50. https://doi.org/10.1515/bsrj-2017-0004

2. Basri S.W., Siam R.M. (2017), Maximizing the social media potential for small businesses and startups: A conceptual study, „International Journal of Economic Perspectives”, volume 11., issue 2., pp. 241-245.

3. Constantinescu M. (ed.) (2019), Attitude evaluation on using the neuromarketing approach in social media: Matching company's purposes and consumer's benefits for sustainable business growth, „Sustainability”, volume 11., issue 24., pp. 1-21. https://doi.org/10.3390/su11247094

4. Grizane T., Jurgelane I. (2017), Social media impact on business evaluation, „Procedia Computer Science", volume 104. pp. 190-196. https://doi.org/10.1016/i.procs.2017.01.103

5. Jones N., Borgman R. (ed.) (2015), Impact of social media on small business, „Journal of Small Business and Enterprise Development", volume 22., issue 4., pp. 611-632. https://doi.org/10.1108/JSBED-09-2013-0133

6. Li F., Larimo J., (ed.) (2020), Social media marketing strategy: definition, conceptualization, taxonomy, validation, and future agenda, „Journal of the Academy of Marketing Science”, volume 49., pp. 51-70. https://doi.org/10.1007/s11747-020-00733-3

7. Li H. (2021), An empirical study to determine the role of social media in the development of businesses, „Revista Argentina de Clínica Psicológica”, number 1., volume XXX. pp. 961970. https://doi.org/10.24205/03276716.2020.2091

8. Radhakrishnan V., Ugalde B. (2019), Impact of social media application in business organizations, „International Journal of Computer Applications”, number 30., volume 178., pp. 5-10. https://doi.org/10.5120/ijca2019919126

9. Sajid S. (2016), Social media and its role in marketing, „Business and Economics Journal”, volume 7., issue 1., pp. 1-5. https://doi.org/10.4172/2151-6219.1000203

10. Swani K., (ed.) (2017), What messages to post? Evaluating the popularity of social media communications in business versus consumer markets, „Industrial Marketing Management”, volume 62, pp. 77.87. https://doi.org/10.1016/j.indmarman.2016.07.006

11. Tajudeen P.F., Jaafar I.N. (ed.) (2018), Understanding the impact of social media usage among organizations, „Information \& Management”, volume 55., issue 3., pp. 308-321. https://doi.org/10.1016/j.im.2017.08.004

12. Tajvidi R., Karami A. (2021), The effect of social media on firm performance, „Computers in Human Behavior”, volume 115. pp. 1-10. https://doi.org/10.1016/j.chb.2017.09.026

13. Webb H.S., Roberts J.S. (2016), Communication and social media approaches in small businesses, „Journal of Marketing Development and Competitiveness”, number 1., volume 10., pp. 66-79. 